\title{
Three suspected cases of sugammadex-induced anaphylactic shock
}

\author{
Tomonori Takazawa ${ }^{1}$, Yukinari Tomita ${ }^{2}$, Nagahide Yoshida ${ }^{3}$, Akihiro Tomioka ${ }^{4}$, Tatsuo Horiuchi ${ }^{1}$, Chie Nagata ${ }^{1}$, \\ Masaki Orihara ${ }^{1}$, Makiko Hardy Yamada ${ }^{1}$ and Shigeru Saito ${ }^{1}$
}

\begin{abstract}
Background: Sugammadex has a unique mechanism of action and is widely used because of its safety and efficacy. A few recent reports have described allergic reactions to clinical doses of sugammadex. We hereby describe another series of cases of possible anaphylaxis to sugammadex.

Case presentation: We present three suspected cases of sugammadex-induced anaphylactic shock, including a 13-year-old boy who underwent laparoscopic appendectomy, a 75-year-old woman who underwent left knee arthroplasty, and a 34-year-old man who underwent left pansinectomy for sinobronchitis. All three patients received general anesthesia with rocuronium and their tracheas were intubated. Shortly after injection of sugammadex for reversal of rocuronium, all of them experienced a decrease in blood pressure along with mucocutaneous erythema. In the most severe case, reintubation after extubation was required due to difficulty in manual ventilation. All patients recovered with anti-allergic therapy. On later investigation, all three patients had a positive skin reaction to sugammadex.
\end{abstract}

Conclusion: Our results suggest that physicians using sugammadex should be aware of the possibility of sugammadex-induced anaphylaxis.

Keywords: Sugammadex, Anaphylactic shock, General anesthesia

\section{Background}

Sugammadex is widely used in more than 60 countries, including the European Union and Japan, for reversal of the effects of the steroidal neuromuscular blocking agents, rocuronium and vecuronium. Sugammadex acts by encapsulation of the rocuronium molecule, such that no more rocuronium is available for binding with nicotinic acetylcholine receptors in the neuromuscular junction. This action of sugammadex for antagonizing rocuronium is completely different from that of acetylcholinesterase inhibitors, such as neostigmine. Sugammadex is generally thought to be a relatively safe and well-tolerated drug, partly due to the lack of some undesirable effects [1,2]. However, confirmed cases of allergic reactions to clinical doses of sugammadex were recently reported [3-8]. We describe 3 cases in which allergic and positive skin test reactions to sugammadex were observed. They include a

\footnotetext{
* Correspondence: takazawt@gunma-u.ac.jp

'Department of Anesthesiology, Gunma University Graduate School of Medicine, 3-39-22 Showa-machi, Maebashi 371-8511, Japan

Full list of author information is available at the end of the article
}

life-threatening case in which reintubation after extubation was required, probably due to sugammadex-induced anaphylaxis.

\section{Case presentation}

\section{Case 1}

A 13-year old, $40 \mathrm{~kg}, 159 \mathrm{~cm}$ boy underwent laparoscopic appendectomy. Anesthesia was induced with $80 \mathrm{mg}$ propofol, $0.33 \mu \mathrm{g} / \mathrm{kg} / \mathrm{min}$ remifentanil, and $30 \mathrm{mg}$ rocuronium. After an uneventful intubation, anesthesia was maintained with sevoflurane and remifentanil. About 15 minutes after intubation, $50 \mathrm{mg}$ flurbiprofen axetil was administered. During the surgery, oxygen saturation was maintained in the high $90 \%$ range and $\mathrm{ETCO}_{2}$ was within normal limits. Baseline blood pressure (BP) was approximately $116 / 78 \mathrm{~mm} \mathrm{Hg}$, remaining in the $90 / 40 \mathrm{~mm}$ $\mathrm{Hg}$ range for most of the case. Heart rate (HR) remained at 50 to $60 \mathrm{bpm}$. The total operation time was 118 minutes. Before extubation, sugammadex $2 \mathrm{mg} / \mathrm{kg}$ was injected to antagonize residual neuromuscular blockade. Shortly after the injection, the patient's trachea was 
extubated when he was able to breathe spontaneously. After extubation, the patient demonstrated global swelling of the face and a low consciousness level. At this point, his blood pressure fell to unmeasurable values and he developed tachycardia of between 150 and $160 \mathrm{bpm}$. Suspecting a possible allergic reaction to sugammadex, he was treated with $100 \mathrm{mg}$ hydrocortisone and $0.1 \mathrm{mg}$ adrenaline IV. The patient needed to be re-intubated because of difficulty with bag mask ventilation. Blood gas analysis showed hypercapnea $\left(\mathrm{PCO}_{2}=66.4 \mathrm{mmHg}\right)$. His trachea was re-intubated after re-induction of anesthesia with $80 \mathrm{mg}$ propofol and $50 \mathrm{mg}$ rocuronium. Additional treatment with $200 \mathrm{mg}$ aminophylline and $200 \mathrm{mg}$ hydrocortisone was given after the intubation, because the occurrence of an asthmatic attack could not be excluded. The patient stayed in the ICU until his trachea was extubated 17 hours after the event. A prick test with dilutions of propofol, rocuronium, ropivacaine, flurbiprofen axetil, and sugammadex was performed 7 weeks after the operation, which showed an immediate reaction only to sugammadex (Table 1).

\section{Case 2}

A 75-year-old, $71 \mathrm{~kg}, 152 \mathrm{~cm}$ woman underwent left knee arthroplasty. General anesthesia was induced with $130 \mathrm{mg}$ propofol, $0.2 \mu \mathrm{g} / \mathrm{kg} / \mathrm{min}$ remifentanil, and $40 \mathrm{mg}$ rocuronium. Following tracheal intubation, anesthesia was maintained with sevoflurane and remifentanil. Ten minutes after induction of general anesthesia, her BP and HR decreased to $70 / 50 \mathrm{mmHg}$ and $50 \mathrm{bpm}$, respectively. Incremental doses of ephedrine $(8 \mathrm{mg} \times 2), 0.2 \mathrm{mg}$ phenylephrine and $0.5 \mathrm{mg}$ atropine were administered intravenously. Both BP and HR responded well to these treatments and increased to $150 / 70 \mathrm{~mm} \mathrm{Hg}$ and $75 \mathrm{bpm}$, respectively. Twenty minutes before the end of surgery, $50 \mathrm{mg}$ flurbiprofen axetil was administered. The total operation time was 99 minutes. Before extubation, sugammadex $2.8 \mathrm{mg} / \mathrm{kg}$ was administered. Three minutes after the injection of sugammadex, her systolic BP fell to 40/ undetectable $\mathrm{mm} \mathrm{Hg}$, together with thoracic erythema, with no response to $0.2 \mathrm{mg}$ phenylephrine injection. No respiratory symptoms, such as wheezing and high airway resistance, were observed. Suspecting a possible allergic reaction to sugammadex, we intravenously administered $0.5 \mathrm{mg}$ adrenaline, $5 \mathrm{mg}$ chlorpheniramine maleate, $50 \mathrm{mg}$ ranitidine hydrochloride, and $300 \mathrm{mg}$ hydrocortisone. Her BP gradually increased to $160 / 80 \mathrm{mmHg}$ after these treatments. The patient was transferred to the intensive care unit (ICU) without extubation. Her trachea was extubated 15 hours later in the ICU when she was fully awake and hemodynamically stable. She was transferred out of the ICU the following morning. Four weeks after the operation, an intradermal allergy test with dilutions of propofol, rocuronium, flurbiprofen axetil, and sugammadex was performed. A 1:1000 dilution of all the drugs showed a negative reaction. However, a 1:100 dilution of sugammadex resulted in a positive reaction (Table 1).

\section{Case 3}

A 34-year old, $62 \mathrm{~kg}, 159 \mathrm{~cm}$ man underwent left pansinectomy for sinobronchitis. Anesthesia was induced with $100 \mathrm{mg}$ propofol, $0.25 \mu \mathrm{g} / \mathrm{kg} / \mathrm{min}$ remifentanil, and $40 \mathrm{mg}$ rocuronium. Following tracheal intubation, anesthesia was maintained with sevoflurane and remifentanil. During

Table 1 Results of postoperative allergy testing in the three patients with suspected anaphylaxis

\begin{tabular}{|c|c|c|c|c|c|c|}
\hline & Type of allergy test & Drug & Concentration 1:1000 & Concentration 1:100 & Wheal (mm) & Flare $(\mathrm{mm})$ \\
\hline \multirow[t]{6}{*}{ Case 1} & Prick test & Saline & - & N/A & 0 & 0 \\
\hline & & Propofol & - & & 0 & 0 \\
\hline & & Rocuronium & - & & 0 & 0 \\
\hline & & Ropivacaine & - & & 0 & 0 \\
\hline & & Flurbiprofen axetil & - & & 0 & 0 \\
\hline & & Sugammadex & + & & 12 & 25 \\
\hline \multirow[t]{5}{*}{ Case 2} & Intradermal test & Saline & - & - & 0 & 0 \\
\hline & & Propofol & - & - & 0 & 0 \\
\hline & & Rocuronium & - & - & 0 & 0 \\
\hline & & Flurbiprofen axetil & - & - & 0 & 0 \\
\hline & & Sugammadex & - & + & 8 & 25 \\
\hline \multirow[t]{4}{*}{ Case 3} & Intradermal test & Saline & - & - & 0 & 0 \\
\hline & & Flurbiprofen axetil & - & - & 0 & 0 \\
\hline & & Pentazocine & - & - & 0 & 0 \\
\hline & & Sugammadex & $+/-$ & + & 10 & 35 \\
\hline
\end{tabular}

Vial concentrations: propofol $10 \mathrm{mg} / \mathrm{ml}$, rocuronium $10 \mathrm{mg} / \mathrm{ml}$, ropivacaine $7.5 \mathrm{mg} / \mathrm{ml}$, flurbiprofen axetil $10 \mathrm{mg} / \mathrm{ml}$, pentazocine $15 \mathrm{mg} / \mathrm{ml}$, sugammadex $100 \mathrm{mg} / \mathrm{ml}$. 
induction and maintenance of anesthesia, BP, oxygen saturation, and $\mathrm{ETCO}_{2}$ were within normal ranges. The total operation time was 59 minutes. At the end of surgery, $50 \mathrm{mg}$ flurbiprofen axetil, $15 \mathrm{mg}$ pentazocine, and sugammadex $3.2 \mathrm{mg} / \mathrm{kg}$ were injected. One minute after the injection but before extubation, the patient developed intense erythema all over the body, especially on the face and chest. Simultaneously, BP decreased from $100 / 60$ to $70 / 40 \mathrm{mmHg}$, with no respiratory symptoms. $\mathrm{BP}$ recovered to $100 / 60 \mathrm{mmHg}$ after $4 \mathrm{mg}$ ephedrine hydrochloride injection, and the patient was transferred to the recovery unit. Erythema disappeared after treatment with $5 \mathrm{mg}$ chlorpheniramine maleate and $50 \mathrm{mg}$ ranitidine hydrochloride administered intravenously. The patient was transferred out of the recovery room 1 hour after the event and discharged home 6 days later. An intradermal test for flurbiprofen axetil, pentazocine, and sugammadex allergy was performed about 7 weeks after the operation. As shown in Table 1, a 1:1000 dilution of sugammadex induced flare, while a 1:100 dilution of sugammadex induced both flare and wheal.

\section{Discussion}

The etiological diagnosis of perioperative anaphylaxis relies on a triad of evidences, including clinical, biological, and allergological evidence [9]. We report here three cases, in which both clinical symptoms and positive skin test reactions were observed in response to sugammadex injection.

The first line of evidence for diagnosing anaphylaxis includes clinical signs. The National Institute of Allergy and Infectious Disease (NIAID) and the Food Allergy and Anaphylaxis Network (FAAN) proposed clinical criteria for diagnosing anaphylaxis [10]. All three of our cases fulfilled these criteria, as evidenced by the acute onset of symptoms, with involvement of the skin and hypotension.

The second line of evidence for diagnosing anaphylaxis is biological assessment, including plasma histamine and tryptase measurements. Typically, anaphylaxis results from mast cell activation, which causes release of mast cell tryptase into the circulation, although a variety of other pathways, including basophil or complement activation, may combine to produce anaphylaxis. We were unable to perform any blood tests in our patients. The currently available tryptase assay has a relatively low sensitivity; hence, some cases of anaphylaxis might be missed [11]. However, given the high specificity of tryptase assay [12], such assessment should be done for diagnosing anaphylaxis. During anaphylaxis, tryptase peaks by approximately $1 \mathrm{~h}$ and its half-life in the circulation is about $2 \mathrm{~h}$ [11], suggesting that elevation of tryptase can still be seen at least 1-2 hours after onset of the reaction, by which time the patient should be stabilized.
Skin tests, the third line of evidence, remain the gold standard for the detection of IgE-mediated reactions, and involve exposure of the mast cells of the skin of patients who experience anaphylaxis to the suspected allergen [13]. In previous reports, either skin-prick $[3,4]$ or intradermal $[7,8]$ tests were performed to detect hypersensitivity to sugammadex. However, there are no established guidelines with respect to skin testing for hypersensitivity to sugammadex. Moreover, it is still unknown which of the two tests is superior. In our three cases, we performed prick or intradermal tests in the operation room several weeks after the incidents, with drugs to treat anaphylaxis readily available. The results showed a positive reaction to only sugammadex in all cases. We chose relatively low concentrations (i.e., 1:1000 or 1:100) of sugammadex for both prick and intradermal tests to avoid false-positive reactions, because it is known that intradermal tests sometimes produce false-positive reactions [14]. A recent study showed that dilutions of $100 \mathrm{mg} / \mathrm{ml}$ sugammadex at 1:77 and 1:770 for intradermal tests did not cause skin irritation or false positive reactions in 11 volunteers, suggesting that 1:100 and higher dilutions of sugammadex are not likely to produce false-positive reactions [15]. However, it was difficult to exclude the possibility that the positive reaction to sugammadex might have been a non-specific cutaneous irritant effect, because of the lack of a positive control skin test with histamine. In addition to skin tests, tests for serum-specific IgE antibodies and basophil activation using flow-cytometry may also be useful for the diagnosis of anaphylaxis $[11,16,17]$. Taken together, the immediate development of anaphylaxis in response to sugammadex and the results of skin tests were highly suggestive of sugammadex-induced anaphylactic shock, although biological assessments and positive control skin tests were lacking.

None of our patients had prior exposure to sugammadex. Cyclodextrins, one of the components of sugammadex preparations, are present in various foods, which may partly explain the cross-reaction with sugammadex. A recent report suggested that the appropriate dose of sugammadex for reversal of rocuronium should be determined by the results of neuromuscular monitoring [18]. However, we did not monitor neuromuscular transmission in our patients.

Sugammadex-induced anaphylaxis typically presents when the patient is already extubated and is being transferred to the hospital bed, PACU, ICU, etc. [3], time points when the patient is typically less monitored. Therefore, rapid diagnosis and appropriate treatment of anaphylaxis, including administration of adrenaline, oxygen, and large volumes of crystalloids, are required. In the current report, patients 1 and 2 were treated with 0.1 and $0.5 \mathrm{mg}$ adrenaline IV, respectively. Although the maximum intravenous bolus dose of adrenaline recommended by recent 
guidelines for anaphylaxis during anesthesia is variable $[17,19]$, the IV bolus dose of $0.5 \mathrm{mg}$ adrenaline administered to case 2 appears to be a larger dose than that recommended by guidelines.

The Japanese Society of Anesthesiologists has issued a warning about sugammadex-induced anaphylactic shock three times since March 2011. The latest one, issued in June 2013, included 95 cases of sugammadex-related allergies that occurred between April 2010 and January 2013, although with no incidents of death. In all 95 cases, the relationship between the reaction and sugammadex was definitively ascertained by the anesthesiologists. Seventyeight out of 95 cases fulfilled the validated criteria for anaphylaxis [10]. The incidence rate of anaphylactic reactions due to sugammadex was estimated as 29 per million cases, based on the estimated number of patients (3.09 millions) in whom sugammadex was injected during the survey period. The alert also pointed out that the incidence rate may have been underestimated, because the survey was based on spontaneous reports from anesthesiologists and not on prospective studies. It is uncertain whether this incidence rate is higher in Japan than in other countries, because there is no epidemiological survey regarding this so far. The other possibility is that these warnings may simply reflect a high level of sugammadex usage in Japan. The drug company, MSD (Tokyo, Japan), has reported that sugammadex usage in Japan in 2010, in terms of monetary value, was more than 4 times higher than that in Spain, the country that showed the second highest usage in the world.

\section{Conclusion}

We would advise physicians using sugammadex to be aware of the possibility of sugammadex-induced anaphylaxis.

\section{Consent}

Written informed consent was obtained from the patients for publication of this case report. A copy of the written consent is available for review by the Editor of this journal. All treatment and clinical testing were performed in accordance with the ethical standards laid down in the 1964 Declaration of Helsinki and its later amendments.

\section{Competing interests}

The authors declare that they have no competing interests.

\section{Authors' contributions}

Tा: Preparation of the manuscript and involvement in case 1. YT: Anesthesiologist involved in the management of cases 2 and 3. NY and AT: Anesthesiologists involved in the management of case 1. TH: Preparation of the manuscript. CN: Anesthesiologist involved in the management of case 2. MO, MHY, and SS: Preparation of the manuscript. All authors read and approved the final manuscript.

\section{Author details}

'Department of Anesthesiology, Gunma University Graduate School of Medicine, 3-39-22 Showa-machi, Maebashi 371-8511, Japan. ²Department of Anesthesiology, Isesaki Municipal Hospital, 12-1 Tsunatorihoncho, Isesaki 372-0817, Japan. ${ }^{3}$ Department of Anesthesiology, Saiseikai Maebashi Hospital, 564-1 Kamishinden-machi, Maebashi 971-0821, Japan. ${ }^{4}$ Department of Anesthesiology, Gunma Chuo General Hospital, 1-7-13 Kouuncho, Maebashi 371-0025, Japan.

Received: 12 July 2013 Accepted: 30 September 2014

Published: 17 October 2014

\section{References}

1. Paton F, Paulden M, Chambers D, Heirs M, Duffy S, Hunter JM, Sculpher M, Woolacott N: Sugammadex compared with neostigmine/glycopyrrolate for routine reversal of neuromuscular block: a systematic review and economic evaluation. Br J Anaesth 2010, 105(5):558-567.

2. Cammu G, De Kam PJ, Demeyer I, Decoopman M, Peeters PA, Smeets JM, Foubert L: Safety and tolerability of single intravenous doses of sugammadex administered simultaneously with rocuronium or vecuronium in healthy volunteers. Br J Anaesth 2008, 100(3):373-379.

3. Godai K, Hasegawa-Moriyama M, Kuniyoshi T, Kakoi T, Ikoma K, Isowaki S, Matsunaga A, Kanmura Y: Three cases of suspected sugammadex-induced hypersensitivity reactions. Br J Anaesth 2012, 109(2):216-218.

4. Menendez-Ozcoidi L, Ortiz-Gomez JR, Olaguibel-Ribero JM, Salvador-Bravo MJ: Allergy to low dose sugammadex. Anaesthesia 2011, 66(3):217-219.

5. Motoyama Y, Izuta S, Maekawa N, Chuma R: [Case of anaphylactic reaction caused by sugammadex]. Masui 2012, 61(7):746-748.

6. Peeters PA, van den Heuvel MW, van Heumen E, Passier PC, Smeets JM, van lersel T, Zwiers A: Safety, tolerability and pharmacokinetics of sugammadex using single high doses (up to $96 \mathrm{mg} / \mathrm{kg}$ ) in healthy adult subjects: a randomized, double-blind, crossover, placebo-controlled, single-centre study. Clin Drug Investig 2010, 30(12):867-874.

7. Sadleir PH, Russell T, Clarke RC, Maycock E, Platt PR: Intraoperative anaphylaxis to sugammadex and a protocol for intradermal skin testing. Anaes Inten Care 2014, 42(1):93-96.

8. Jeyadoss J, Kuruppu P, Nanjappa N, Van Wijk R: Sugammadex hypersensitivity-a case of anaphylaxis. Anaes Intens Care 2014, 42(1):89-92.

9. Dewachter P, Mouton-Faivre C, Emala CW: Anaphylaxis and anesthesia: controversies and new insights. Anesthesiology 2009, 111(5):1141-1150.

10. Sampson HA, Munoz-Furlong A, Campbell RL, Adkinson NF Jr, Bock SA Branum A, Brown SG, Camargo CA Jr, Cydulka R, Galli SJ, Gidudu J, Gruchalla RS, Harlor AD Jr, Hepner DL, Lewis LM, Lieberman PL, Metcalfe DD, O'Connor R, Muraro A, Rudman A, Schmitt C, Scherrer D, Simons FE, Thomas S, Wood JP, Decker WW: Second symposium on the definition and management of anaphylaxis: summary report-Second National Institute of Allergy and Infectious Disease/Food Allergy and Anaphylaxis Network symposium. J Allergy Clin Immunol 2006, 117(2):391-397.

11. Harper NJ, Dixon T, Dugue P, Edgar DM, Fay A, Gooi HC, Herriot R, Hopkins P, Hunter JM, Mirakian R, Pumphrey RS, Seneviratne SL, Walls AF, Williams P, Wildsmith JA, Wood P, Nasser AS, Powell RK, Mirakhur R, Soar J: Suspected anaphylactic reactions associated with anaesthesia. Anaesthesia 2009, 64(2):199-211.

12. Mertes PM, Laxenaire MC, Alla F, Groupe d'Etudes des Reactions Anaphylactoides P: Anaphylactic and anaphylactoid reactions occurring during anesthesia in France in 1999-2000. Anesthesiology 2003, 99(3):536-545.

13. Dewachter $P$, Mouton-Faivre $C$ : What investigation after an anaphylactic reaction during anaesthesia? Curr Opin Anesthesio 2008, 21(3):363-368.

14. Fisher M, Baldo BA: Anaphylaxis during anaesthesia: current aspects of diagnosis and prevention. Eur J Anaesthesiol 1994, 11(4):263-284.

15. Clarke RC, Sadleir PH, Platt PR: The role of sugammadex in the development and modification of an allergic response to rocuronium: evidence from a cutaneous model. Anaesthesia 2012, 67(3):266-273.

16. Ewan PW, Dugue P, Mirakian R, Dixon TA, Harper JN, Nasser SM, Bsaci: $\mathrm{BSACl}$ guidelines for the investigation of suspected anaphylaxis during general anaesthesia. Clin Exper allergy 2010, 40(1):15-31.

17. Kroigaard M, Garvey LH, Gillberg L, Johansson SG, Mosbech H, Florvaag E, Harboe T, Eriksson LI, Dahlgren G, Seeman-Lodding H, Takala R, Wattwil M, Hirlekar G, Dahlén B, Guttormsen AB: Scandinavian Clinical Practice Guidelines on the 
diagnosis, management and follow-up of anaphylaxis during anaesthesia. Acta anaesthesiologica Scandinavica 2007, 51(6):655-670.

18. Kotake Y, Ochiai R, Suzuki T, Ogawa S, Takagi S, Ozaki M, Nakatsuka I,

Takeda J: Reversal with sugammadex in the absence of monitoring did not preclude residual neuromuscular block. Anesth Analg 2013, 117(2):345-351.

19. Mertes PM, Malinovsky JM, Jouffroy L, Working Group of the S, Sfa, Aberer W, Terreehorst I, Brockow K, Demoly P, ENDA; EAACI Interest Group on Drug Allergy: Reducing the risk of anaphylaxis during anesthesia: 2011 updated guidelines for clinical practice. Journal Invest Allergology Clinical Immun 2011, 21(6):442-453.

doi:10.1186/1471-2253-14-92

Cite this article as: Takazawa et al:: Three suspected cases of sugammadex-induced anaphylactic shock. BMC Anesthesiology 2014 14:92.

\section{Submit your next manuscript to BioMed Central and take full advantage of:}

- Convenient online submission

- Thorough peer review

- No space constraints or color figure charges

- Immediate publication on acceptance

- Inclusion in PubMed, CAS, Scopus and Google Scholar

- Research which is freely available for redistribution 